\title{
Cytoprotective role of humanin in lens epithelial cell oxidative stress-induced injury
}

\author{
HAO YANG $^{1}$, YILEI CUI ${ }^{1}$, YELEI TANG ${ }^{2}$, XIAJING TANG ${ }^{1}$, XIAONING YU $^{1}$, \\ JIAYUE ZHOU $^{1}$, QICHUAN YIN ${ }^{1}$ and XINGCHAO SHENTU ${ }^{1}$ \\ ${ }^{1}$ Zhejiang Provincial Key Lab of Ophthalmology Eye Center, The Second Affiliated Hospital, \\ School of Medicine, Zhejiang University; ${ }^{2}$ Department of Neurology, School of Medicine, \\ Zhejiang University, Hangzhou, Zhejiang 310009, P.R. China
}

Received October 9, 2019; Accepted April 15, 2020

DOI: $10.3892 / \mathrm{mmr} .2020 .11202$

\begin{abstract}
Oxidative stress-induced injury and apoptosis of human lens epithelial cells (HLECs) are early events in the development of age-related cataracts (ARCs). Humanin (HN) is a mitochondrial-related peptide that serves a cytoprotective role in various cell types and animal models. Following HN knockdown or overexpression, the level of reactive oxygen species (ROS), mitochondrial membrane potential and mitochondrial DNA copy number, cell viability, LDH activity and apoptosis of HLECs under oxidative stress were detected, and apoptosis and autophagy were detected via transmission electron microscopy. The results suggested that HN may be involved in the response of HLECs to oxidative stress, and that HN expression was significantly upregulated under oxidative stress conditions. Furthermore, exogenous HN reduced intracellular ROS content and mitochondrial damage, and enhanced mitochondrial biosynthesis; however, this protection was lost in an endogenous HN knockdown cell model. In addition, to the best of our knowledge, the present study was the first to identify that HN increased mitochondrial autophagy, which was involved in reducing ROS production under oxidative stress. The present study indicated a potential mechanism underlying the anti-oxidative damage and apoptotic effects of HN under oxidative stress. In conclusion, $\mathrm{HN}$ may be a potential therapeutic target for ARCs as it has a significant
\end{abstract}

Correspondence to: Dr Xingchao Shentu, Zhejiang Provincial Key Lab of Ophthalmology Eye Center, The Second Affiliated Hospital, School of Medicine, Zhejiang University, 88 Jiefang Road, Hangzhou, Zhejiang 310009, P.R. China

E-mail: stxc@zju.edu.cn

Abbreviations: HLECs, human lens epithelial cells; ARCs, age-related cataracts; HN, humanin; MDP, mitochondrial-derived peptide; ROS, reactive oxygen species; T2DM, type 2 diabetes mellitus; AMD, age-related macular degeneration; CCK-8, Cell Counting Kit-8; mtDNA, mitochondrial DNA; $\Delta \psi \mathrm{m}$, mitochondrial membrane potential

Key words: ARCs, HN, ROS, oxidative stress, HLECs cellular protective effect on HLECs under oxidative stress; therefore, further study is required to investigate its role in the occurrence and development of ARCs.

\section{Introduction}

Age-related cataracts (ARCs) are characterized by an increase in the opacity of the lens with age; however, there are currently no effective drugs that can inhibit or reverse the progression of ARCs (1). The exact mechanism of ARC development is not fully understood, but it has been confirmed that oxidative stress serves a key role in its pathogenesis (2). UV rays, nutrient starvation, $\mathrm{H}_{2} \mathrm{O}_{2}$ in aqueous humor, amongst other factors can damage the lens by oxidative stress, particularly via oxidative damage to human lens epithelial cells (HLECs) (3). HLECs are a thin layer of cells in the anterior lens capsule that are responsible for the defense of the lens against oxidative stress and are therefore vulnerable to oxygen free radicals (3). Under oxidative stress, reactive oxygen species (ROS), a byproduct of metabolism, accumulate in HLECs and cause oxidative damage to nucleic acids, lipids and organelles, eventually leading to apoptosis (4-6). Furthermore, apoptosis of HLECs is considered to be an early event in the development of cataracts (4,5,7-9). In response to oxidative stress, particularly the increase in ROS production in HLECs, lens proteins are denatured, modified and aggregated, which eventually leads to cataract formation (10). In addition, oxidative stress has been shown to induce lens opacification in experimental animal models and in cultured rat lenses (11).

Humanin (HN) was the first identified mitochondrial-derived peptide (MDP), which comprises 21-24 amino acids expressed by the open reading frame of mitochondrial $16 \mathrm{~S}$ rRNA (12). HN is expressed in various tissues, including neuronal cells, skeletal muscle cells (13), retinal pigment epithelial cells (14) and blood-derived cells (15). Previous studies have reported that HN may serve a role in metabolic regulation and antioxidant injury in nerve cells, cardiomyocytes, epidermal stem cells and other cell types, as well as in pathological models, such as Alzheimer's disease, type 2 diabetes mellitus (T2DM) and age-related macular degeneration (AMD). These effects include $\mathrm{H}_{2} \mathrm{O}_{2}$-induced cell death (16), $\beta$-amyloid toxicity (17), serum starvation-induced 
neuronal cell death (18) and protective effects of oxidized low-density lipoproteins-induced vascular endothelial cell death (19). Furthermore, knockdown of endogenous HN increased the sensitivity of cells to apoptosis induced by oxidative stress (12). However, to the best of our knowledge, there have been no previous studies examining the expression and function of HN in HLECs, and the role of $\mathrm{HN}$ in the prevention or treatment of ARCs.

Considering the important role of oxidative stress and ROS in the pathogenesis of cataracts, the present study investigated the role of HN in HLECs under oxidative stress and its underlying mechanisms. Moreover, the present study examined the relationship between $\mathrm{HN}$ and the formation of ARCs, by administering exogenous HN or knocking down endogenous $\mathrm{HN}$ to assess whether $\mathrm{HN}$ can reduce oxidative damage and apoptosis.

\section{Materials and methods}

Cell culture and treatment. HLECs (HLE-B3; American Type Culture Collection) were grown and maintained in 1:1 DMEM and Ham's F-12 medium (DMEM/F-12; cat. no. 10-092-CV; Corning, Inc.), which was supplemented with $10 \%$ FBS (Biological Industries) and 100 units penicillin and streptomycin (Gibco; Thermo Fisher Scientific, Inc.) at $37^{\circ} \mathrm{C}$ with $5 \%$ $\mathrm{CO}_{2}$. HN peptides were chemically synthesized and purified to $>95 \%$ purity (Nanjing Taiye Chemical Industry Co., Ltd.). The HN group was incubated with DMEM containing $50 \mu \mathrm{M}$ $\mathrm{HN}$ at $37^{\circ} \mathrm{C}$ for $2 \mathrm{~h}$ before receiving type B UV (UVB) radiation. In the small interfering RNA (siRNA) HN group, HN siRNA was transfected into cells using Lipofectamine ${ }^{\circledR} 3000$ (Invitrogen; Thermo Fisher Scientific, Inc.) for $48 \mathrm{~h}$, after which, cells received UVB radiation. For the rescue experiment, the siHN group was incubated with DMEM containing $50 \mu \mathrm{M} \mathrm{HN}$ at $37^{\circ} \mathrm{C}$ for $2 \mathrm{~h}$ prior to UVB radiation. For serum starvation, after pretreatment with $50 \mu \mathrm{M} \mathrm{HN}$ for $2 \mathrm{~h}$ or transfection with siHN for $48 \mathrm{~h}$, cells were incubated in serum-free medium after being rinsed twice with PBS, for $72 \mathrm{~h}$ before experiments. Cells incubated in DMEM containing 10\% FBS were considered the nutrients group.

For UVB irradiation, cells were treated as aforementioned, rinsed with PBS and treated with a given dose of UVB $\left(0,10,20,30\right.$ and $50 \mathrm{~mJ} / \mathrm{cm}^{2} ; 37^{\circ} \mathrm{C}$; air). Cells were exposed to UVB light (from the bottom) in PBS $\left(37^{\circ} \mathrm{C}\right.$; air) for $2.5 \mathrm{~min}$ using a Spectroline 'medium wave' UV lamp (Spectroline) at a distance of $0.8 \mathrm{~cm}$. Control cells were treated similarly, but were not exposed to UVB light. UVB levels reaching the cells were determined with a radiometer (UVX Digital; UVP, Inc.) equipped with a UVB sensor at $312 \mathrm{~nm}$ (UVX-31). Following UVB exposure, cells were rinsed twice with PBS and cultured for $24 \mathrm{~h}$ in DMEM containing 10\% FBS. The morphological analysis of HLECs was conducted using a fluorescence microscope (Leica Microsystems GmbH; magnification, x400).

RNA interference. The siRNAs were designed and synthesized by Guangzhou Ribobio Co., Ltd. The sequence of HN-specific siRNA was: 5'-GGGUUCAGCUGUCUCUUA C-3'. A nonsilencing siRNA (cat. no. SI03650318; Qiagen, Inc.) was used as a negative control. At $50 \%$ confluence, cells were transfected with siRNA (5 nmol/l) using Lipofectamine ${ }^{\circledR} 3000$
(Invitrogen; Thermo Fisher Scientific, Inc.). A total of $48 \mathrm{~h}$ post-transfection, subsequent experiments were performed. Control transfection was also performed using Lipofectamine ${ }^{\circledR}$ 3000 without nucleic acids (Mock). The knockdown of HN was confirmed by reverse transcription-quantitative PCR (RT-qPCR) and western blotting.

$R T-q P C R$. Total RNA was extracted from cells using TRIzol ${ }^{\circledR}$ reagent (Thermo Fisher Scientific, Inc.). Total RNA concentration was estimated by spectrophotometry. Total RNA was reverse transcribed into cDNA using the PrimeScript RT reagent kit (Takara Biotechnology Co., Ltd.). qPCR was performed using Power SYBR Green PCR Master Mix (cat. no. 4367659; Thermo Fisher Scientific, Inc.) and the StepOnePlus RT PCR system (Applied Biosystems; Thermo Fisher Scientific, Inc.) to investigate the expression levels of apoptosis, autophagy, endoplasmic reticulum (ER) stress and antioxidant-associated genes. Each sample was run in triplicate. The following thermocycling conditions were used for qPCR: Initial denaturation for $1 \mathrm{~min}$ at $94^{\circ} \mathrm{C}$, followed by 30 cycles of $30 \mathrm{sec}$ at $94^{\circ} \mathrm{C}, 30 \mathrm{sec}$ at $60^{\circ} \mathrm{C}, 2 \mathrm{~min}$ at $72^{\circ} \mathrm{C}$; and a final extension step at $72^{\circ} \mathrm{C}$ for $5 \mathrm{~min}$. RT-qPCR data were analyzed using the $2^{-\Delta \Delta \mathrm{Cq}}$ method (20). $\Delta \mathrm{Cq}$ was the difference between the quantification cycle $(\mathrm{Cq})$ of the target gene and $\mathrm{Cq}$ of the housekeeper gene (reference gene). $\Delta \Delta \mathrm{Cq}$ was calculated by subtracting $\Delta \mathrm{Cq}$ of each experimental group from $\Delta \mathrm{Cq}$ of the control group. Fold change was calculated using the following formula: Fold-change $=2^{-\Delta \Delta \mathrm{Cq}}$.

The primers used for RT-qPCR were as follows: Human NADH dehydrogenase 1 (ND1) forward, 5'-ATACCCATG GCCAACCTCCT-3' and reverse, 5'-GGGCCTTTGCGTAGT TGTAT-3'; human $\beta$-globin forward, 5'-GTGCACCTGACT CCTGAGGAGA-3' and reverse, 5'-CCTTGATACCAACCT GCCCAG-3'; $\beta$-actin, forward, 5'-GAGAGGGAAATCGTG CGTGAC-3' and reverse, 5'-CTGCTGGAAGGTGGACAG TGAG-3'; HN, forward, 5'-CTCCACGAGGGTTCAGCT GT-3' and reverse, 5'-TTATGTCCGCCTCTTCACGG-3'; and human GAPDH, forward, 5'-GGTGAAGGTCGGAGTCAA CG-3' and reverse, 5'-CAAAGTTGTCATGGATGHACC-3'.

Cell viability assay. Cytotoxicity was assessed using a Cell Counting Kit-8 (CCK-8) assay (Dojindo Molecular Technologies, Inc.). Briefly, $24 \mathrm{~h}$ before UVB treatment, $1 \times 10^{4}$ cells were seeded in each well of a 96-well plate. Cells were rinsed twice with PBS and treated with a given dose of UVB $\left(0,10,20,30\right.$ and $50 \mathrm{~mJ} / \mathrm{cm}^{2} ; 37^{\circ} \mathrm{C}$; air). Following incubation for $24 \mathrm{~h}$, the medium was removed, and the cells were washed with PBS. Each well was then refilled with $90 \mu 1$ DMEM/F12 supplemented with $10 \%$ FBS and $10 \mu \mathrm{l} \mathrm{CCK}-8$ reagents, which was incubated at $37^{\circ} \mathrm{C}$ for $3 \mathrm{~h}$. Cell viability was evaluated at an optical density of $450 \mathrm{~nm}$ using a 96-well microplate reader (Bio-Rad Laboratories, Inc.).

Lactate dehydrogenase ( $L D H)$ cytotoxicity assay. The percentage of living cells was determined using a LDH Cytotoxicity assay kit (Beyotime Institute of Biotechnology). Briefly, $1 \times 10^{4}$ cells were seeded in each well of a 96-well plate and incubated for $24 \mathrm{~h}$. Cells were rinsed twice with PBS and treated with a given dose of UVB $\left(0\right.$ or $30 \mathrm{~mJ} / \mathrm{cm}^{2} ; 37^{\circ} \mathrm{C}$; air). After incubation for $24 \mathrm{~h}$, the culture media was collected 
and centrifuged for $5 \mathrm{~min}$ at 2,442 $\mathrm{x} \mathrm{g}$ at room temperature. The supernatant was dispensed into a 96-well plate and LDH assay reagent was added to each well. The plate was incubated at room temperature for $30 \mathrm{~min}$. Absorbance values were measured at $450 \mathrm{~nm}$ using a microplate reader. The living cells $(\%)$ was calculated as follows: Cytotoxicity $(\%)=($ absorbance of test sample-absorbance of low control)/(absorbance of maximum enzyme activity-absorbance of low control) x100.

Measurement of intracellular ROS. ROS were measured using 2',7'-dichlorofluorescein diacetate (DCFH-DA, Beyotime Institute of Biotechnology). Following incubation for $24 \mathrm{~h}$ after UVB exposure, HLECs were washed three times with PBS. DCFH-DA, diluted to a final concentration of $10 \mu \mathrm{M}$, was added to HLECs and incubated for $30 \mathrm{~min}$ at $37^{\circ} \mathrm{C}$ in the dark. After the cells were washed three times with serum-free medium, the fluorescence intensity was detected with a multi-detection microplate reader with excitation at $488 \mathrm{~nm}$ and emission at $530 \mathrm{~nm}$ within $15 \mathrm{~min}$. Fluorescence signals were captured using a fluorescence microscope (Leica Microsystems $\mathrm{GmbH}$ ). Intracellular levels of ROS were calculated by the average fluorescence intensity as analyzed by Image-Pro Plus software (version 6.0; National Institutes of Health). The measured fluorescence values were expressed as a percentage of the fluorescence in control cells.

Mitochondrial membrane potential $(\Delta \Psi m)$ measurement. JC- 1 was used to measure the $\Delta \Psi \mathrm{m}$ of HLECs. Briefly, $5 \times 10^{5}$ cells were collected into $2 \mathrm{ml}$ tubes and incubated with $10 \mu \mathrm{g} / \mathrm{ml} \mathrm{JC}-1$ for $20 \mathrm{~min}$ at $37^{\circ} \mathrm{C}$. The fluorescence intensity was detected with a flow cytometer (BD FACSAria I cell sorter; Becton, Dickinson and Company). The wavelengths of excitation and emission were 514 and $529 \mathrm{~nm}$, for detection of the monomeric form of JC-1. In addition, 585 and $590 \mathrm{~nm}$ were used to detect aggregation of JC-1. The ratio of aggregated JC-1 and monomeric JC-1 represented the $\Delta \Psi \mathrm{m}$ of HLECs. The data were analyzed using Quantity One software (version 4.6.6; National Institutes of Health). Images were captured by fluorescence microscopy (Leica Microsystems $\mathrm{GmbH}$; magnification, $\mathrm{x} 400$ ).

Transmission electron microscopy (TEM). Cells were fixed for $2 \mathrm{~h}$ at $4^{\circ} \mathrm{C}$ in glutaraldehyde and paraformaldehyde (3 and 4\%, respectively) in $0.1 \mathrm{M}$ cacodylate buffer ( $\mathrm{pH} 7.2$ ). After washing in $0.1 \mathrm{M}$ cacodylate buffer, cells were post-fixed with $1 \%$ osmium tetroxide in $0.1 \mathrm{M}$ cacodylate buffer $(\mathrm{pH} 7.2)$ for $1 \mathrm{~h}$ at room temperature. Cells were dehydrated using a graded acetone series and embedded in EPON-82 resin (Sigma-Aldrich; Merck KGaA) for $72 \mathrm{~h}$ at $60^{\circ} \mathrm{C}$. Ultra-thin sections $(80 \mathrm{~nm})$ were stained with uranyl acetate $(5 \%$; $10 \mathrm{~min})$ and lead citrate $(2 \% ; 30 \mathrm{~min})$ at room temperature and observed using a JEM-1200EX TEM (magnification, $\mathrm{x} 25,000$; JEOL Ltd.) at $120 \mathrm{~V}$. Data were analyzed using Image-Pro Plus software (version 6.0; National Institutes of Health).

Cell apoptosis assay. Cells of each experimental group $\left(5 \times 10^{6}\right.$ cells $\left./ \mathrm{ml}\right)$ were cultured in $35 \mathrm{~mm}^{2}$ dishes and incubated for $24 \mathrm{~h}$. Cells were rinsed twice with PBS and treated with a given dose of UVB $\left(0\right.$ or $30 \mathrm{~mJ} / \mathrm{cm}^{2} ; 37^{\circ} \mathrm{C}$; air $)$. After $24 \mathrm{~h}$ incubation, cells were collected by trypsinization and centrifugation at $2442 \times \mathrm{g}$ for $5 \mathrm{~min}$. The cell pellet was washed twice with cold PBS and resuspended in $1 \mathrm{X}$ Annexin-binding buffer (BD Biosciences). Subsequently, the cell suspension $(100 \mu \mathrm{l})$ was incubated with $5 \mu \mathrm{l}$ Annexin V and $1 \mu \mathrm{l} 100 \mu \mathrm{g} / \mathrm{ml}$ PI working solution (BD Biosciences) at room temperature for $15 \mathrm{~min}$ in the dark. After the incubation, $400 \mu 1$ 1X Annexin-binding buffer was added. After mixing, the fluorescence intensity was detected with a flow cytometer (CyAn ADP; Beckman Coulter, Inc.) at 530 and $575 \mathrm{~nm}$ emission, and $488 \mathrm{~nm}$ excitation. BD FACSdiva Software (version 8.0.1; BD Biosciences) was used to analyze the data. The percentage of cells stained by AnnexinV ${ }^{+} / \mathrm{PI}^{-}$, which indicates early apoptosis, was presented as a bar chart.

Determination of mitochondrial DNA (mtDNA) copy number. The mtDNA copy number was defined as the total mtDNA copies divided by the total nuclear DNA (nDNA) copies. qPCR was performed to measure the mtDNA and nDNA copies of each experimental group. Total DNA of the cells in each experimental group was extracted using the DNA/RNA Isolation kit (Qiagen $\mathrm{GmbH}$ ) according to the manufacturer's instructions. For each qPCR, $1 \mu \mathrm{l}$ sample DNA (10 ng/ $\mu \mathrm{l})$ was amplified in a $10-\mu 1$ reaction mixture that contained $0.25 \mu \mathrm{l}$ each primer ( $20 \mu \mathrm{M}$; human ND1 for mtDNA; human $\beta$-globin for nDNA; $\beta$-actin reference gene), $5 \mu 1$ SensiFAST SYBR Hi-ROX premix (Thermo Fisher Scientific, Inc.) and $3.5 \mu 1$ PCR-grade water. In each experiment, $1 \mu 1$ HLECs DNA $(1 \mathrm{ng} / \mu \mathrm{l})$ and PCR-grade water were used as the positive and negative controls, respectively. The following thermocycling conditions were used for qPCR: Initial denaturation for $30 \mathrm{sec}$ at $95^{\circ} \mathrm{C}$; followed by 45 cycles of denaturation for $15 \mathrm{sec}$ at $95^{\circ} \mathrm{C}$, annealing for $20 \mathrm{sec}$ at $60^{\circ} \mathrm{C}$, extension for $20 \mathrm{sec}$ at $72^{\circ} \mathrm{C}$. After obtaining $\mathrm{Cq}$ values, the mtDNA copies and nDNA copies of the sample DNA (10 ng) relative to those of HLECs were determined according to the aforementioned equations.

Western blotting. After treatment, total protein was extracted from HLECs using RIPA lysis buffer (cat. no. r0020; Beijing Solarbio Science \& Technology Co, Ltd.) and a bicinchoninic acid protein assay kit (cat. no. B9643-1L; Sigma-Aldrich; Merck $\mathrm{KGaA}$ ) was used to determine the total protein concentration. Equal concentrations of total protein samples ( $8 \mu \mathrm{l} /$ lane) were loaded into the wells of $4-12 \%$ Bolt mini gels (Thermo Fisher Scientific, Inc.) followed by SDS-PAGE. The proteins were then transferred onto PVDF membranes. Following transfer, membranes were blocked with $5 \%$ fat-free milk in TBS for $30 \mathrm{~min}$ at room temperature and then incubated with primary antibodies against HN (cat. no. LS-C109400; 1:2,000; LifeSpan BioSciences), Bcl-2 (cat. no. 4223; 1:2,000; Cell Signaling Technology, Inc), Bax (cat. no. 5023; 1:2,000; Cell Signaling Technology, Inc.), cleaved caspase 3 (cat. no. 9665; 1:2,000; Cell Signaling Technology, Inc.) and $\beta$-actin (cat. no. sc-47778; 1:5,000; Santa Cruz Biotechnology, Inc.) overnight at $4^{\circ} \mathrm{C}$. Subsequently, goat anti-mouse $\mathrm{IgG}$ H\&L (cat. no. ab205719; 1:5,000; Abcam) and goat anti-rabbit IgG H\&L (cat. no. ab205718; 1:5,000; Abcam) horseradish peroxidase-conjugated secondary antibodies or $2 \mathrm{~h}$ at room temperature. Protein bands were visualized using the SuperSignal $^{\mathrm{TM}}$ Western Blot Substrate bundle (Pierce; Thermo 
Fisher Scientific, Inc.). Data were analyzed using Image-Pro Plus 6.0 software (version 6.0; National Institutes of Health).

Statistical analysis. Statistical analysis was performed using one-way ANOVA followed by Tukey post hoc test using GraphPad InStat (version 3.05; GraphPad Software, Inc.). Data are presented as the mean $\pm \mathrm{SD}$. $\mathrm{P}<0.05$ was considered to indicate a statistically significant difference. Each experiment was repeated at least three times.

\section{Results}

HN expression in HLECs is associated with oxidative stress. It was revealed that $24 \mathrm{~h}$ after UVB treatment, the morphology of HLECs changed (Fig. 1A); UVB induced cell loss, disordered intracellular structure and enhanced the appearance of apoptotic bodies. Moreover, the higher the UVB dose used to treat HLECs, the more significant the change in cell morphology, indicating that the cells were under high oxidative stress. To further investigate the relationship between endogenous HN expression and oxidative stress, RT-qPCR was used to detect the mRNA expression levels of HN in HLECs treated with various doses of UVB $\left(0,10,30\right.$ and $50 \mathrm{~mJ} / \mathrm{cm}^{2}$; Fig. 1B). It was demonstrated that the expression levels of $\mathrm{HN}$ were increased $12 \mathrm{~h}$ after UVB irradiation and HN expression was positively associated with UVB exposure. Moreover, the mRNA expression levels of $\mathrm{HN}$ were upregulated by $62 \%(\mathrm{P}<0.05)$ at the dose of $10 \mathrm{~mJ} / \mathrm{cm}^{2}, 138 \%(\mathrm{P}<0.01)$ at $30 \mathrm{~mJ} / \mathrm{cm}^{2}$ and $219 \%$ $(\mathrm{P}<0.01)$ at $50 \mathrm{~mJ} / \mathrm{cm}^{2}$ compared with the control group. Therefore, the present results suggested that UVB irradiation may induce upregulation of HN in HLECs, and that HN may be involved in the response of cells to oxidative stress.

$H N$ protects HLECs from oxidative damage. To investigate whether HN has a protective effect on HLECs under oxidative stress, a HN knockdown cell line was established by gene silencing. qPCR and western blot analysis of $\mathrm{HN}$ were performed and it was confirmed by qPCR analysis that the expression of $\mathrm{HN}$ was downregulated by $83 \%$ compared with the notransfection group (Fig. 2A and B). In addition, a CCK-8 assay was used to detect the viability of HLECs (Fig. 2C). The results revealed that knockdown of $\mathrm{HN}$ significantly decreased the viability of HLECs $(\mathrm{P}<0.05)$. In addition, the present study treated the HN knockdown group with different levels of UVB; the results demonstrated that cell viability was reduced by $\sim 50 \%$ in the control group treated with UVB irradiation $\left(30 \mathrm{~mJ} / \mathrm{cm}^{2}\right)$ and by $77 \%(\mathrm{P}<0.01)$ in the HN knockdown group compared with the control group (0 UVB; Fig. 2C). Therefore, $30 \mathrm{~mJ} / \mathrm{cm}^{2}$ was used as the UVB irradiation dose in follow-up experiments. The viability of HLECs pretreated with various doses of exogenous HN $24 \mathrm{~h}$ after UVB irradiation was then measured (Fig. 2D). It was demonstrated that the cellular protective effect of $\mathrm{HN}$ was dose-dependent, but there was no significant increase in response to $100 \mu \mathrm{M} \mathrm{HN}$ compared with $50 \mu \mathrm{M} \mathrm{HN}$; therefore, the present study used $50 \mu \mathrm{M} \mathrm{HN}(\mathrm{P}<0.01)$ as the concentration of exogenous HN in the follow-up experiments. Furthermore, $30 \mathrm{~mJ} / \mathrm{cm}^{2} \mathrm{UVB}$ exerted significant cytotoxicity on HLECs $(\mathrm{P}<0.01)$. However, pretreatment with $\mathrm{HN}$ reduced UVB cytotoxicity $(\mathrm{P}<0.05)$ and reduced LDH activity by $20 \%$ (Fig. 2E), whereas knockdown
A

0

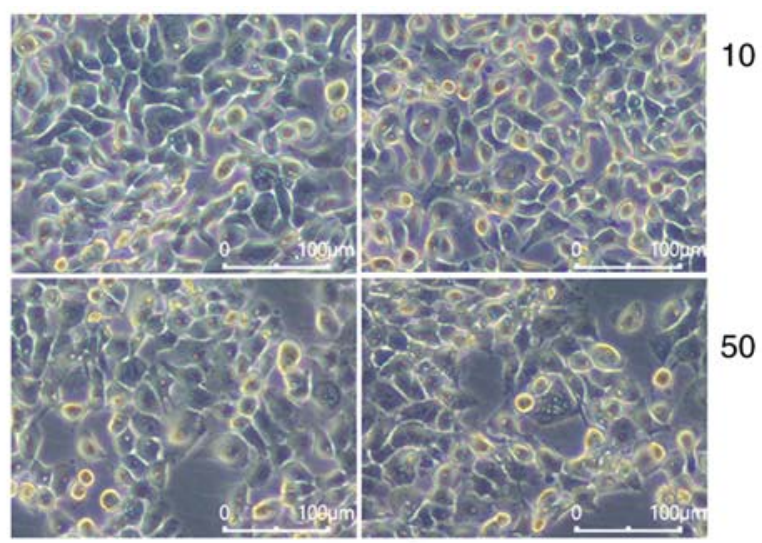

UVB $\left(\mathrm{mJ} / \mathrm{cm}^{2}\right)$

B

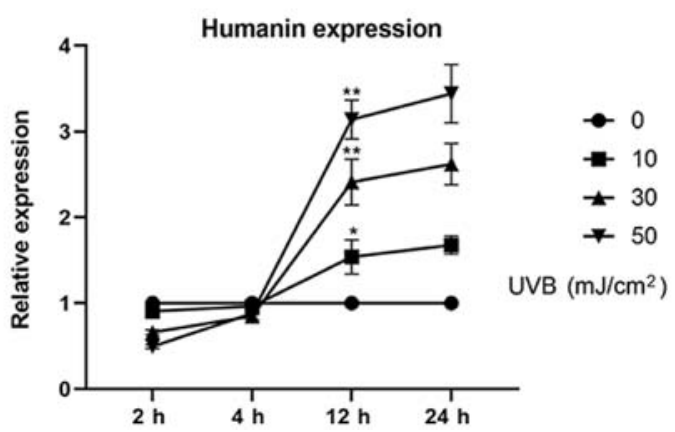

Figure 1. Expression of HN in HLECs at different levels of oxidative stress (A) Images of HLECs $24 \mathrm{~h}$ after exposure to a $0,10,30$ or $50 \mathrm{~mJ} / \mathrm{cm}^{2}$ dose of UVB. (B) HLECs were subjected to different doses of UVB $(0,10$, 30 or $50 \mathrm{~mJ} / \mathrm{cm}^{2}$ ), and the mRNA expression levels of $\mathrm{HN}$ were detected by reverse transcription-quantitative PCR at 2, 4, 12 and $24 \mathrm{~h}$. Data are presented as the mean $\pm \mathrm{SD}, \mathrm{n}=3$. ${ }^{*} \mathrm{P}<0.05,{ }^{* *} \mathrm{P}<0.01$ vs. $12 \mathrm{~h} 0 \mathrm{~mJ} / \mathrm{cm}^{2} \mathrm{UVB}$. HN, humanin; HLECs, human lens epithelial cells; UVB, type B UV.

of HN significantly increased the sensitivity of HLECs to UVB cytotoxicity $(\mathrm{P}<0.01)$. Collectively, the present results indicated that HN may effectively protect HLECs from oxidative damage induced by UVB.

HN inhibits ROS production in HLECs. Under oxidative stress, the level of ROS in cells increases significantly (4). ROS derived from damaged mitochondria are important physiological signaling molecules that regulate gene expression, apoptosis and cell proliferation $(5,6)$. Excessive ROS can further impair mitochondrial function and affect cell viability $(21,22)$. Therefore, the present study hypothesized that HN may reduce the production of ROS in HLECs and act as an antioxidant. The present study detected intracellular ROS using the fluorescent probe DCFH-DA, and it was found that the level of ROS in HLECs increased under oxidative stress (Fig. 3). In addition, the level of ROS in the HN siRNA group was significantly higher compared with the control group, regardless of whether there was UVB treatment. However, HLECs pretreated with $50 \mu \mathrm{M}$ HN under oxidative stress showed lower ROS levels compared with the UVB-treated control group $(\mathrm{P}<0.05)$. Thus, the present results suggested that $\mathrm{HN}$ can significantly reduce ROS production in HLECs under oxidative stress.

HN protects mitochondria from oxidative stress in HLECs. The present study identified a significant increase in ROS 
A

흠
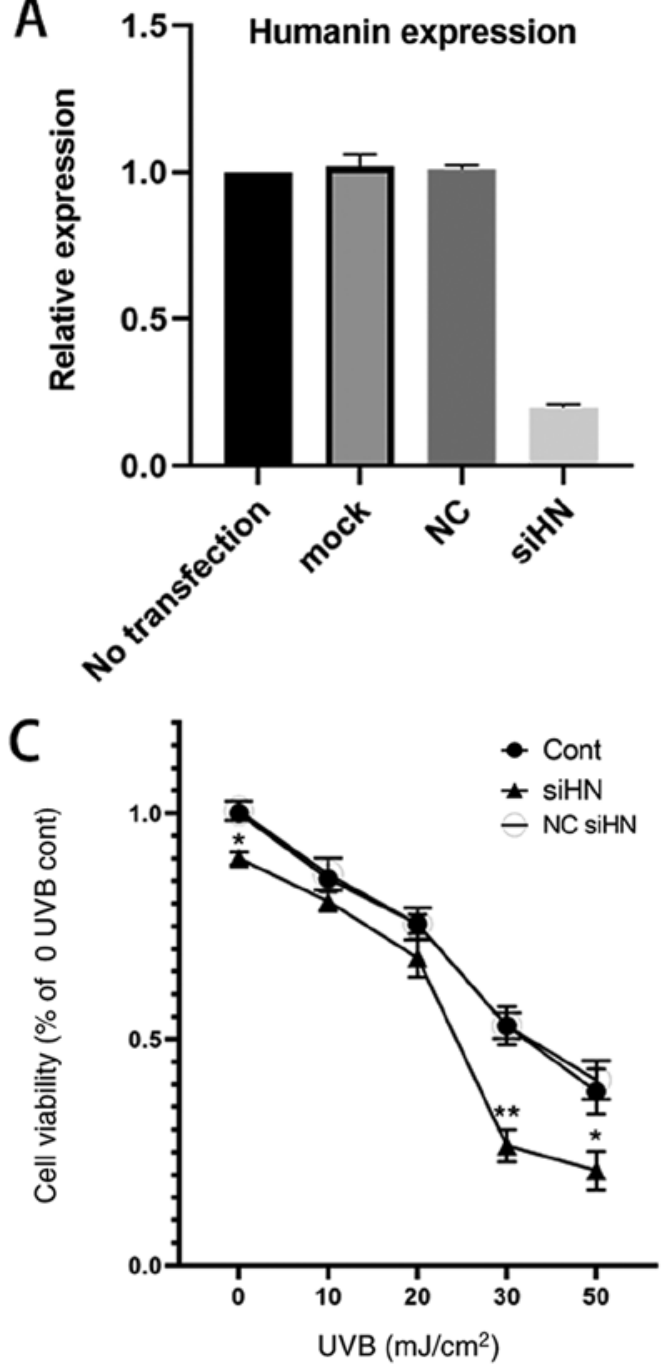

E

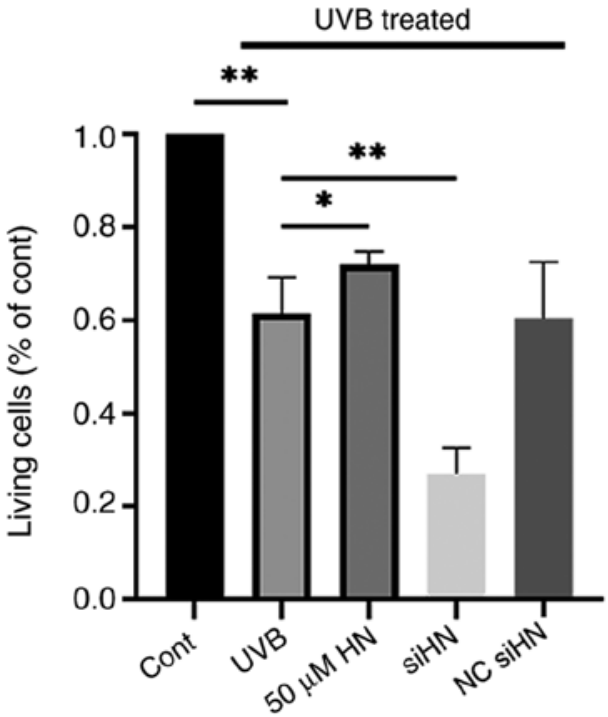

B
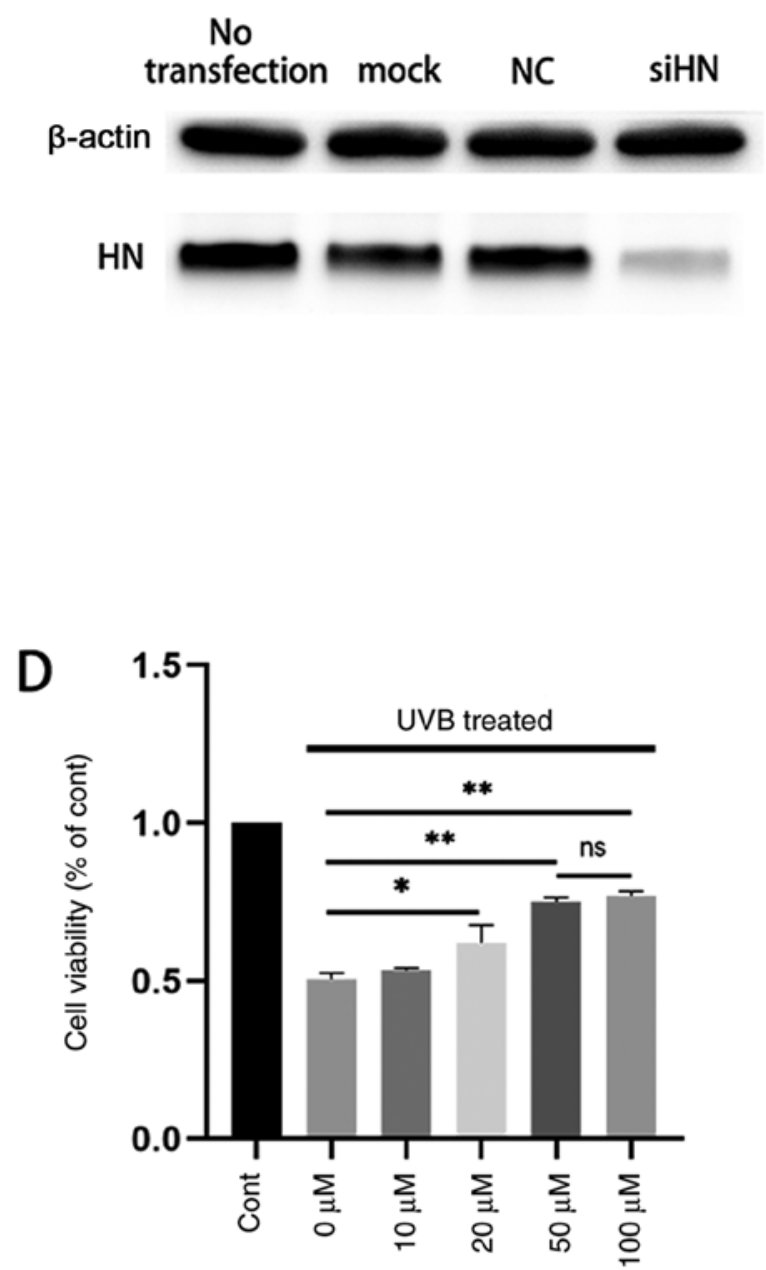

$\mathrm{HN}$

Figure 2. Effects of HN on the viability and LDH cytotoxicity of HLECs subjected to UVB. (A and B) Cells were transfected with siHN for $48 \mathrm{~h}$. NC siHN group cells were transfected with NC siRNA for $48 \mathrm{~h}$. Mock transfection was performed using Lipofectamine ${ }^{\circledR} 3000$ without nucleic acids. (A) mRNA expression levels of HN were detected by reverse transcription-quantitative PCR. (B) Protein expression levels of HN were examined using western blotting. (C and D) Cell Counting Kit-8 assay. (C) After transfection with siHN and NC siRNA for $48 \mathrm{~h}$, the cells were washed twice with PBS, and HLECs were subjected to different doses $\left(0,10,20,30\right.$ and $\left.50 \mathrm{~mJ} / \mathrm{cm}^{2}\right)$ of UVB. (D) After incubation with a given concentration $(0,10,20,50$ or $100 \mu \mathrm{M})$ of $\mathrm{HN}$ for $2 \mathrm{~h}$, the cells were washed twice with PBS, and HLECs were treated with UVB at a dose of $30 \mathrm{~mJ} / \mathrm{cm}^{2}$. (E) After pretreatment with $50 \mu \mathrm{M} \mathrm{HN}$ for $2 \mathrm{~h}$ or transfection with siHN or NC siRNA for $48 \mathrm{~h}$, the cells were washed twice with PBS, and then HLECs were subjected to UVB radiation at a dose of $30 \mathrm{~mJ} / \mathrm{cm}^{2}$. After $24 \mathrm{~h}$, $\mathrm{LDH}$ release was determined using a commercial kit. Data are presented as the mean $\pm \mathrm{SD}, \mathrm{n}=3 .{ }^{*} \mathrm{P}<0.05$ and ${ }^{* *} \mathrm{P}<0.01 \mathrm{vs}$. Cont. HN, humanin; LDH, lactate dehydrogenase; HLECs, human lens epithelial cells; UVB, type B UV; siHN, HN siRNA; siRNA, small interfering RNA; NC, negative control; Cont, control. 
levels in UVB-treated HLECs, which aggravated mitochondrial damage under oxidative stress. Due to the poor repair ability of mtDNA, damage to mtDNA can cause energy metabolism disorders, apoptosis and cell necrosis (23). To further investigate whether $\mathrm{HN}$ is involved in mitochondrial protection, the present study detected the $\Delta \psi \mathrm{m}$ using JC-1 staining. JC-1 aggregates in normal mitochondria and has red fluorescence. It was found that UVB treatment increased green fluorescence in HLECs, indicating a decrease in $\triangle \psi \mathrm{m}$ and an increase in depolarizing mitochondria (Fig. 4A). A decrease in $\Delta \psi \mathrm{m}$ is also considered an important event during early apoptosis (23). Moreover, the $\mathrm{HN}$-administered group exhibited a higher red-green fluorescence ratio after UVB treatment compared with the control group $(\mathrm{P}<0.01)$, whereas the HN siRNA group had a significantly lower red-green fluorescence ratio compared with the control group and the HN knockdown group supplemented with exogenous $\mathrm{HN}$ ( $\mathrm{P}<0.01$; Fig. 4B). The present study also examined the mtDNA copy number to assess the degree of mtDNA damage and biosynthesis (Fig. 4C). It was demonstrated that HN knockdown resulted in a decrease in mitochondrial copy number under oxidative stress $(\mathrm{P}<0.01)$. However, exogenous HN significantly reversed the damage to mitochondria in the siHN group $(\mathrm{P}<0.01)$. Moreover, the number of mitochondria per cell was counted after $24 \mathrm{~h}$ of UVB irradiation by TEM (Fig. 4D). Consistent with the results of mtDNA copy number, exogenous $\mathrm{HN}$ could increase mitochondrial number in HLECs induced by oxidative stress (Fig. 4E; $\mathrm{P}<0.05$ ). Furthermore, a significant increase in mitochondrial autophagosomes was identified (Fig. 4D) in HLECs administered with exogenous HN compared with the UVB control cells, thus HN may enhance mitophagy (Fig. 4F). This allows HLECs to remove damaged mitochondria in time to prevent ROS accumulation within cells (24). In summary, the present results indicated that $\mathrm{HN}$ has a beneficial effect on mitochondrial damage and biosynthesis in HLECs under oxidative stress.

HN protects HLECs from oxidative stress-induced apoptosis. Under oxidative stress, elevated levels of intracellular ROS and damaged mitochondria can lead to apoptosis, which is also considered to be an early event in the development of cataracts (2). To investigate the effect of $\mathrm{HN}$ on oxidative stress-induced apoptosis of HLECs, cells were stained with Annexin V-FITC/PI to analyze the apoptotic rate of HLECs induced by UVB (Fig. 5A) or serum starvation (Fig. S1) using flow cytometry. HLECs exhibited significant apoptosis after UVB irradiation or serum starvation $(\mathrm{P}<0.001)$, and apoptosis in the HN siRNA group was more significant compared with the control group with or without oxidative stress (Fig. 5A and B; $\mathrm{P}<0.01)$. Under UVB irradiation, $\mathrm{HN}$-pretreated cell apoptosis was decreased by $11 \%$ compared with the control group $(\mathrm{P}<0.05)$, while under serum starvation, $\mathrm{HN}$-pretreated cell apoptosis was decreased by $42 \%$ compared with the control group $(\mathrm{P}<0.01)$. Thus, exogenous $\mathrm{HN}$ may serve a moderate protective role in UVB-induced HLEC apoptosis. Compared with the control group, oxidative stress significantly increased the protein expression levels of Bax and cleaved caspase-3, and decreased the expression levels of Bcl-2 ( $\mathrm{P}<0.01$; Fig. 5C). Furthermore, under UVB treatment, the $\mathrm{HN}$-administered group displayed higher Bcl-2 expression levels compared with the control group (37.5\%; $\mathrm{P}<0.05$; Fig. 5D), but $17(\mathrm{P}<0.05)$ and $18 \%(\mathrm{P}<0.05)$ lower Bax and cleaved caspase 3 expression levels compared with the control group. Collectively, the present results suggested that $\mathrm{HN}$ may inhibit apoptosis by regulating the expression levels of $\mathrm{Bcl}-2$ and $\mathrm{Bax}$, and the activation of caspase-3.

\section{Discussion}

Epidemiology has linked oxidative stress to the development of cataracts, and oxidative stress-induced apoptosis of HLECs has been reported as a key early event of ARC development $(22,25,26)$. The in vitro experiments suggested that $\mathrm{HN}$ may act as an antioxidant MDP in HLECs. To the best of our knowledge, the present study was the first to identify that exogenous $\mathrm{HN}$ enhanced the resistance of HLECs to oxidative stress and reduced apoptosis by inhibiting the production of ROS, preventing the decrease of $\Delta \psi \mathrm{m}$, increasing mitochondrial membrane biosynthesis and enhancing the autophagy of mitochondria. Furthermore, it was revealed that HN knockdown increased the sensitivity of HLECs to oxidative damage and led to increased apoptosis.

The present study revealed that $\mathrm{HN}$ was expressed in HLECs and responded to oxidative stress. The level of ROS in HLECs has previously been reported to be positively associated with the dose of UVB and induced different degrees of oxidative stress in cells (27). The results indicated that 4-12 $\mathrm{h}$ after UVB irradiation, HN expression increased, which was associated with UVB irradiation. Thus, HN, as a highly conserved cytoprotective peptide, may have an important role in the survival mechanism of HLECs under oxidative stress. HN expression in various tissues and cells, as well as age-related pathological models, has been reported to be associated with oxidative stress resistance $(13,19,28)$. It was previously shown that $\mathrm{HN}$ expression was elevated in polarized retinal pigment epithelium monolayers, which increased their resistance to oxidative stress (14). Moreover, HN levels were downregulated in patients with T2DM, which reduced their antioxidant capacity (29).

Under oxidative pressure $(29,30)$, characteristic changes in cells include a significant increase in intracellular ROS and mitochondrial depolarization (31). High concentrations of ROS in cells may cause oxidative injury to lipids, proteins and nucleic acids, and could damage the integrity of various biomolecules (23). In addition, excessive ROS may have a central role in the pathogenesis of various human diseases, such as cataracts, cardiovascular disease, AMD, diabetes and aging $(32,33)$. The oxidative phosphorylation process of depolarized mitochondria is a major source of intracellular ROS $(34,35)$. Furthermore, mitochondria are sensitive to oxidative stress, and the repair of mtDNA is slower compared with that of nDNA (23). Decreased resistance to oxidative damage or lack of rapid removal of damaged mitochondria may result in a significant accumulation of ROS within the cell, which may cause more severe oxidative damage to mitochondria and various biomolecules (36), and eventually lead to apoptotic cell death $(31,34)$. Therefore, reducing ROS production and protecting mitochondrial function are critical for HLEC resistance to oxidative stress. The present study revealed that knockdown of $\mathrm{HN}$ resulted in a significant 
A

Cont

HN

siHN

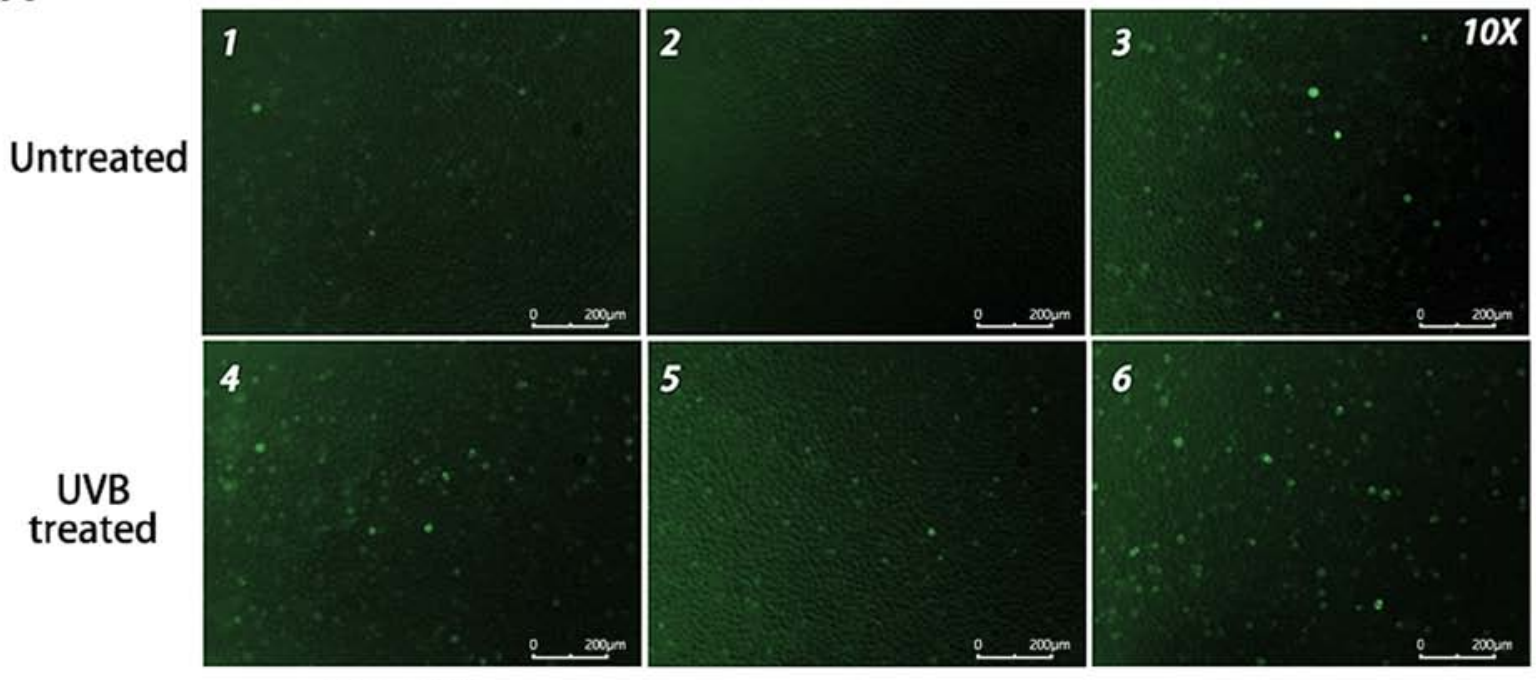

NC-siHN
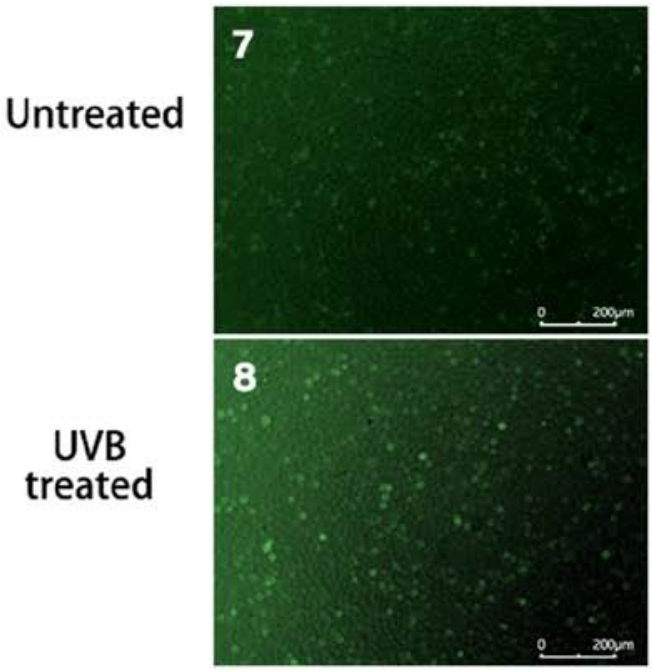

B

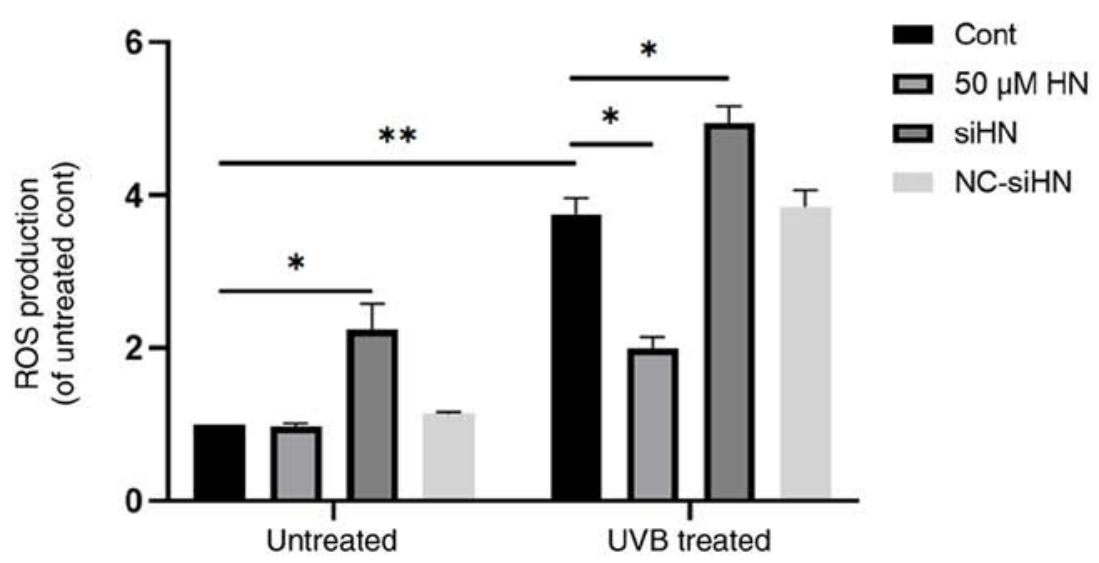

Figure 3. Endogenous HN inhibits UVB-induced ROS production in HLECs. After pretreatment with $50 \mu \mathrm{M} H \mathrm{H}$ for $2 \mathrm{~h}$ or transfection with siHN or NC siRNA for $48 \mathrm{~h}$, HLECs were subjected to $30 \mathrm{~mJ} / \mathrm{cm}^{2} \mathrm{UVB}$ radiation. After $24 \mathrm{~h}$, intracellular ROS levels were determined by $2^{\prime}, 7^{\prime}$-dichlorofluorescein diacetate. (A) Observation under a fluorescence microscope and (B) detection by a fluorescence microplate reader. Data are presented as the mean \pm SD, $\mathrm{n}=3 .{ }^{*} \mathrm{P}<0.05,{ }^{* *} \mathrm{P}<0.01$. HN, humanin; HLECs, human lens epithelial cells; UVB, type B UV; ROS, reactive oxygen species; siHN, HN siRNA; siRNA, small interfering RNA; NC, negative control; Cont, control.

increase in the levels of ROS in HLECs, particularly under oxidative stress, whereas exogenous HN significantly reduced the levels of ROS in HLECs under oxidative stress. The present study hypothesized that the primary reason for this was that the expression of endogenous HN may be important for cells to maintain a low level of ROS, and under oxidative 
A

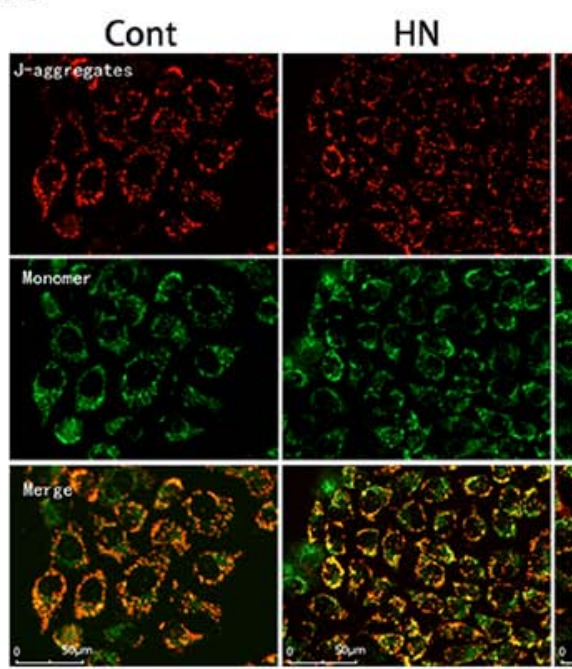

Untreated

siHN $\mathrm{siHN}+\mathrm{HN}$
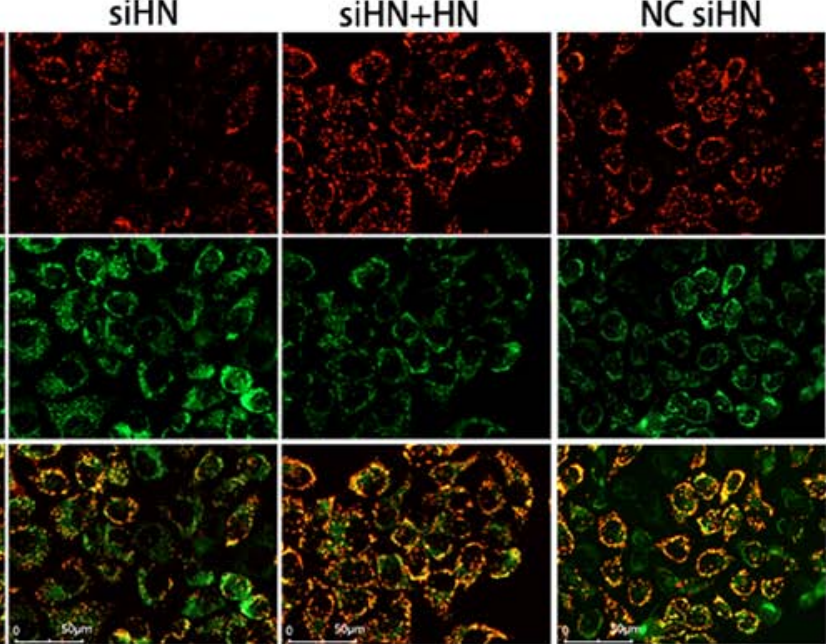

UVB treated
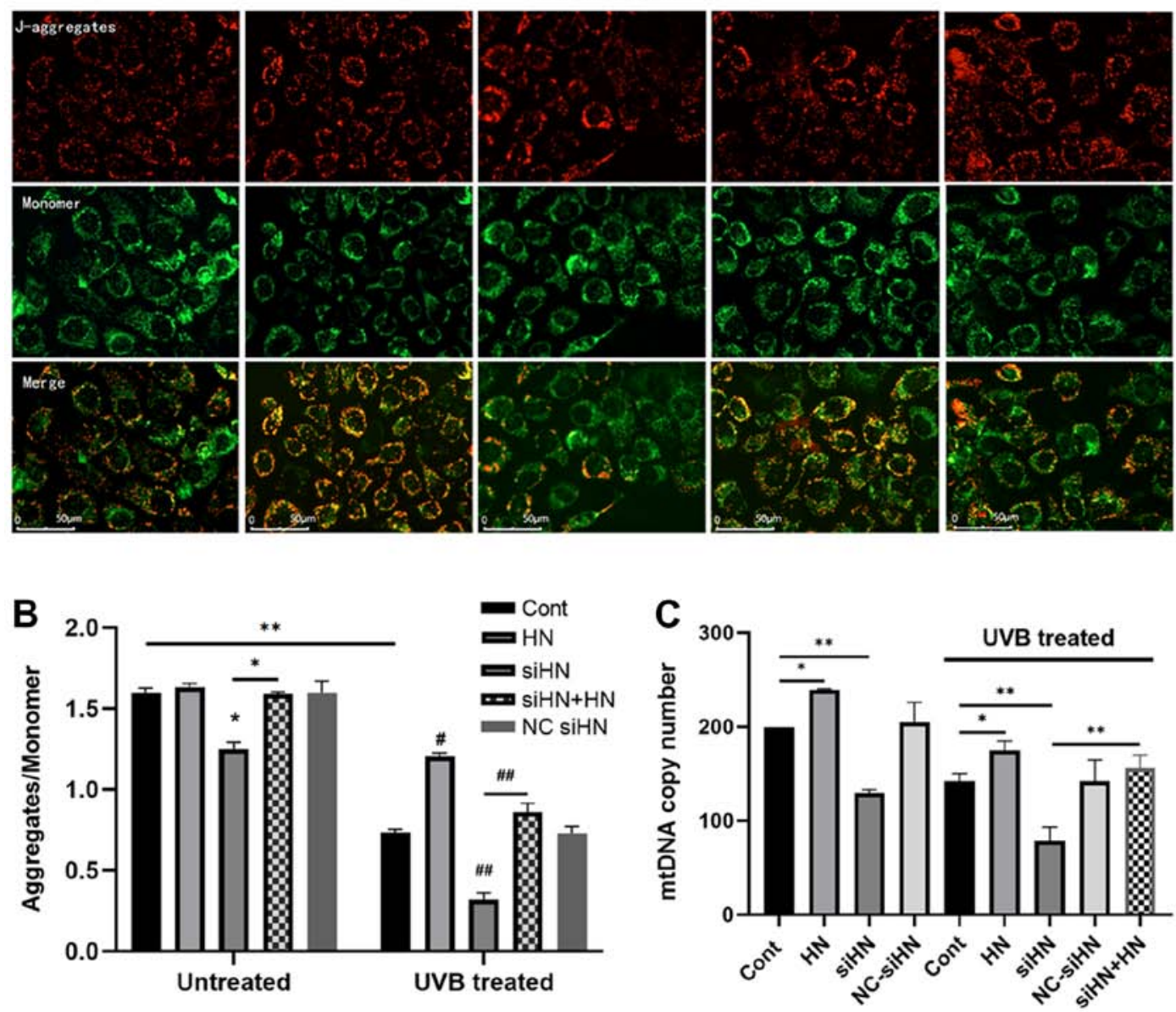

Figure 4. HN protects mitochondria from oxidative stress in HLECs. After pretreatment with $50 \mu \mathrm{M}$ HN for $2 \mathrm{~h}$ or transfection with siRNA for $48 \mathrm{~h}$, HLECs were subjected to $30 \mathrm{~mJ} / \mathrm{cm}^{2} \mathrm{UVB}$ radiation. (A) Red fluorescence represents the mitochondrial aggregate form of JC-1, indicating an intact $\Delta \Psi \mathrm{m}$. Green fluorescence represents the monomeric form of JC-1, indicating dissipation of $\Delta \Psi \mathrm{m}$. (B) Detection by a fluorescence microplate reader. The ratio of red to green fluorescence indicates the ratio of JC-1 aggregates/monomer. Data are presented as the mean \pm SD, n=6. (C) Determination of mtDNA copy number. After $24 \mathrm{~h}$ of cultivation, ND1 and $\beta$-actin expression levels were detected by reverse transcription-quantitative PCR.

stress HN reduces the production of endogenous ROS via its protective effect against mitochondrial damage. Moreover, it was found that $\mathrm{HN}$ effectively enhanced mitochondrial resistance to oxidative stress, and that exogenous HN pretreatment significantly increased $\Delta \psi \mathrm{m}$ in UVB-treated HLECs. In addition, it was demonstrated that $\mathrm{HN}$ co-treatment rescued the increased sensitivity of mitochondria to oxidative stress. Furthermore, the present results suggested that the changes in $\mathrm{HN}$ altered mitochondrial biosynthesis and mitochondrial numbers. In HLECs with HN knockdown, the mtDNA copy number was significantly reduced compared with the control group, whereas exogenous HN could rescue this reduction 


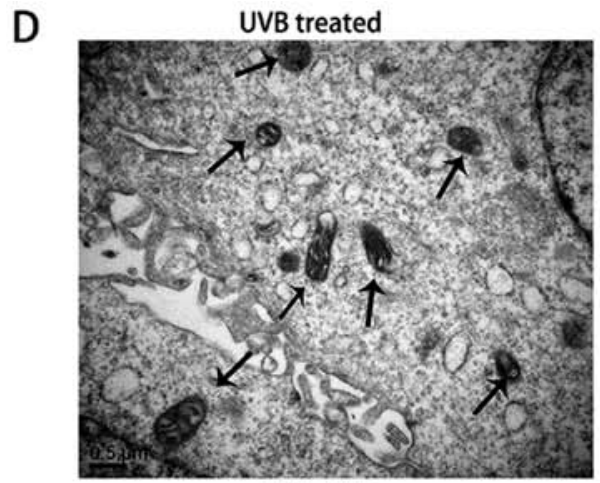

SiHN+UVB

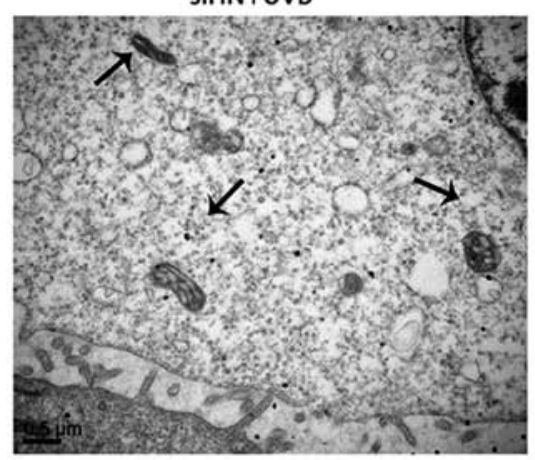

$s i H N+50 \mu M H N+U V B$

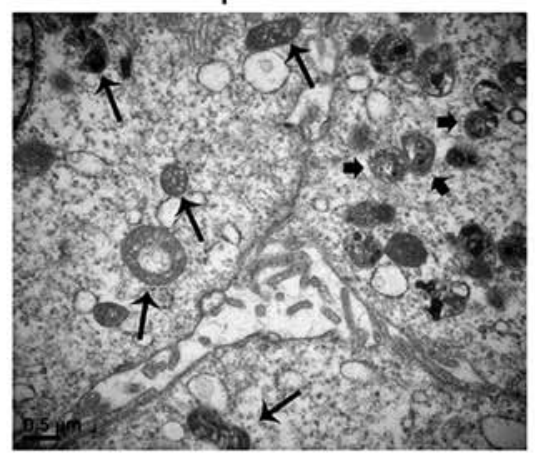

E

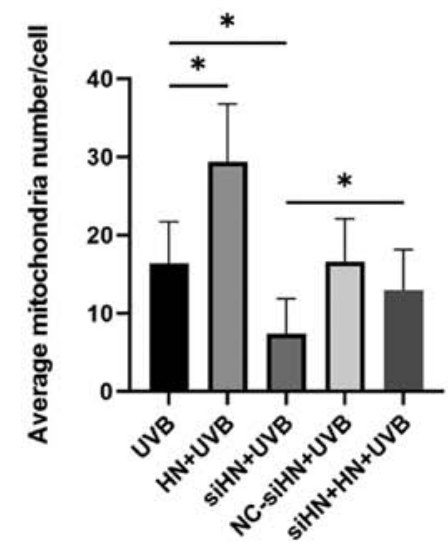

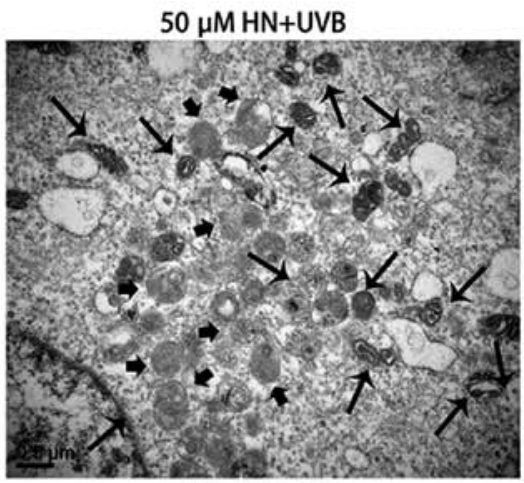

NC-siHN+UVB

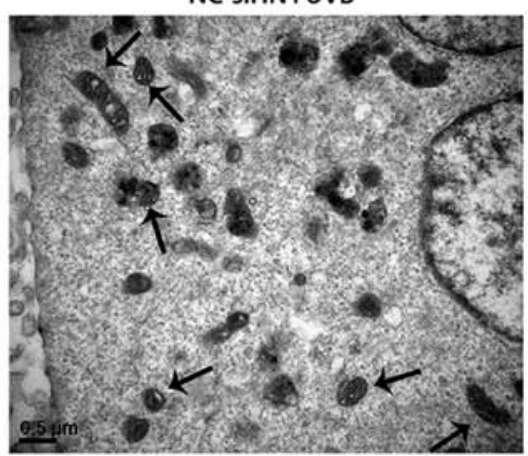

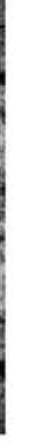

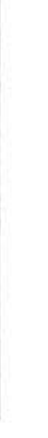

$\mathrm{F}$

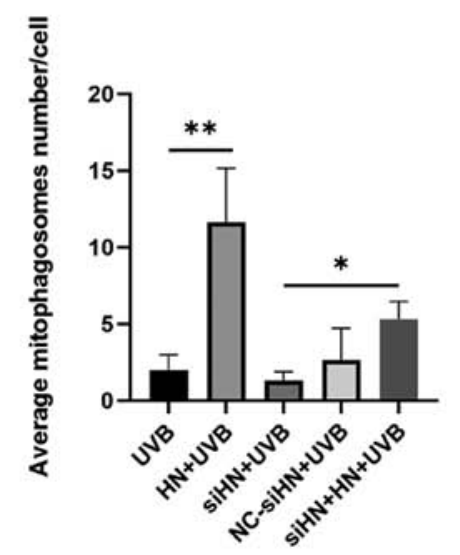

Figure 4. Continued. HN protects mitochondria from oxidative stress in HLECs. After pretreatment with $50 \mu \mathrm{M} H \mathrm{HN}$ for $2 \mathrm{~h}$ or transfection with siRNA for $48 \mathrm{~h}$, HLECs were subjected to $30 \mathrm{~mJ} / \mathrm{cm}^{2} \mathrm{UVB}$ radiation. ((D) Mitochondria and mitophagosomes were detected by TEM (magnification, $\left.\mathrm{x} 25,000 \mathrm{X}\right)$. The thin arrow indicates mitochondria and the thick arrow indicates mitochondrial autophagosomes. (E) Average number of mitochondria per cell. Record the number of mitochondria in 15 cells and get the average value. (F) Average number of mitophagosomes per cell. Record the number of mitochondria in 15 cells and get the average value. Data are presented as the mean $\pm \mathrm{SD}, \mathrm{n}=3 .{ }^{*} \mathrm{P}<0.05,{ }^{* *} \mathrm{P}<0.01 . \Delta \Psi \mathrm{m}$, mitochondrial membrane potential; mtDNA, mitochondrial DNA; HN, humanin; HLECs, human lens epithelial cells; UVB, type B UV; siHN, HN siRNA; siRNA, small interfering RNA; NC, negative control; Cont, control.

in mtDNA copy number, as verified by the TEM results. Sreekumar et al (15) reported that HN upregulated the expression of mitochondrial transcription factor A, a key biogenesis regulator protein, to regulate mitochondrial transcription initiation $(37,38)$. Similarly, the present results indicated that $\mathrm{HN}$ increased the copy number of mtDNA with or without 
A
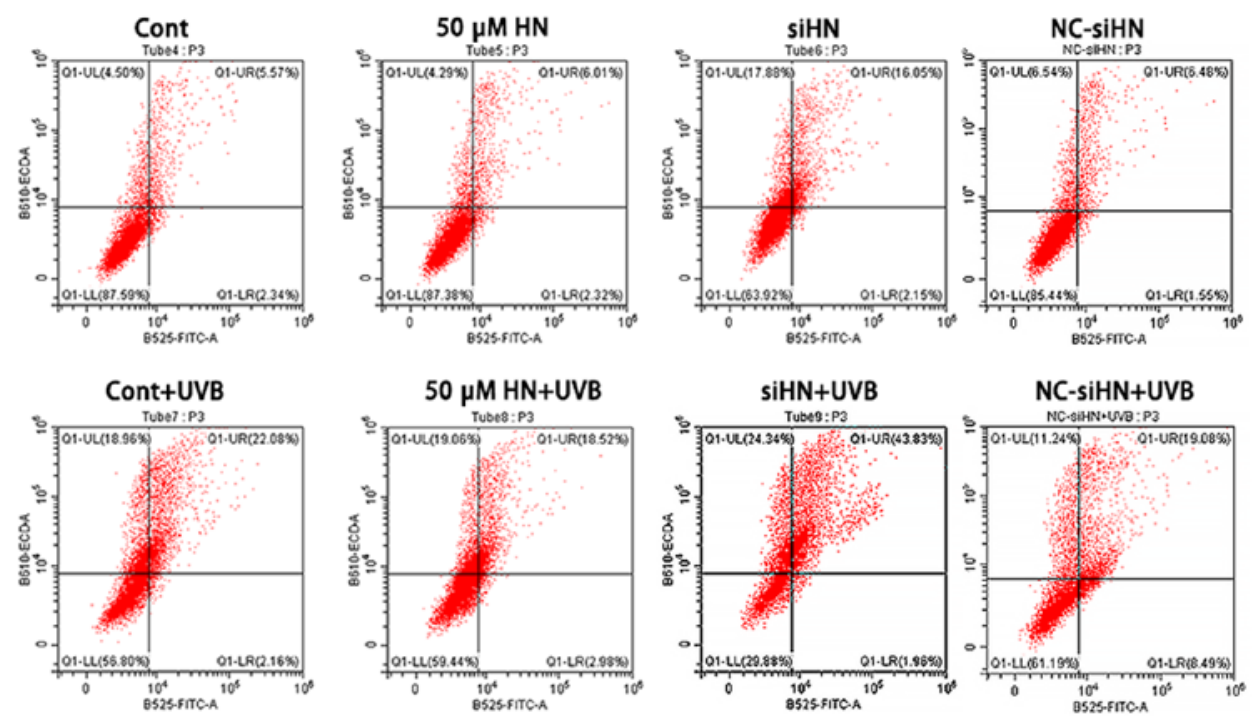

B
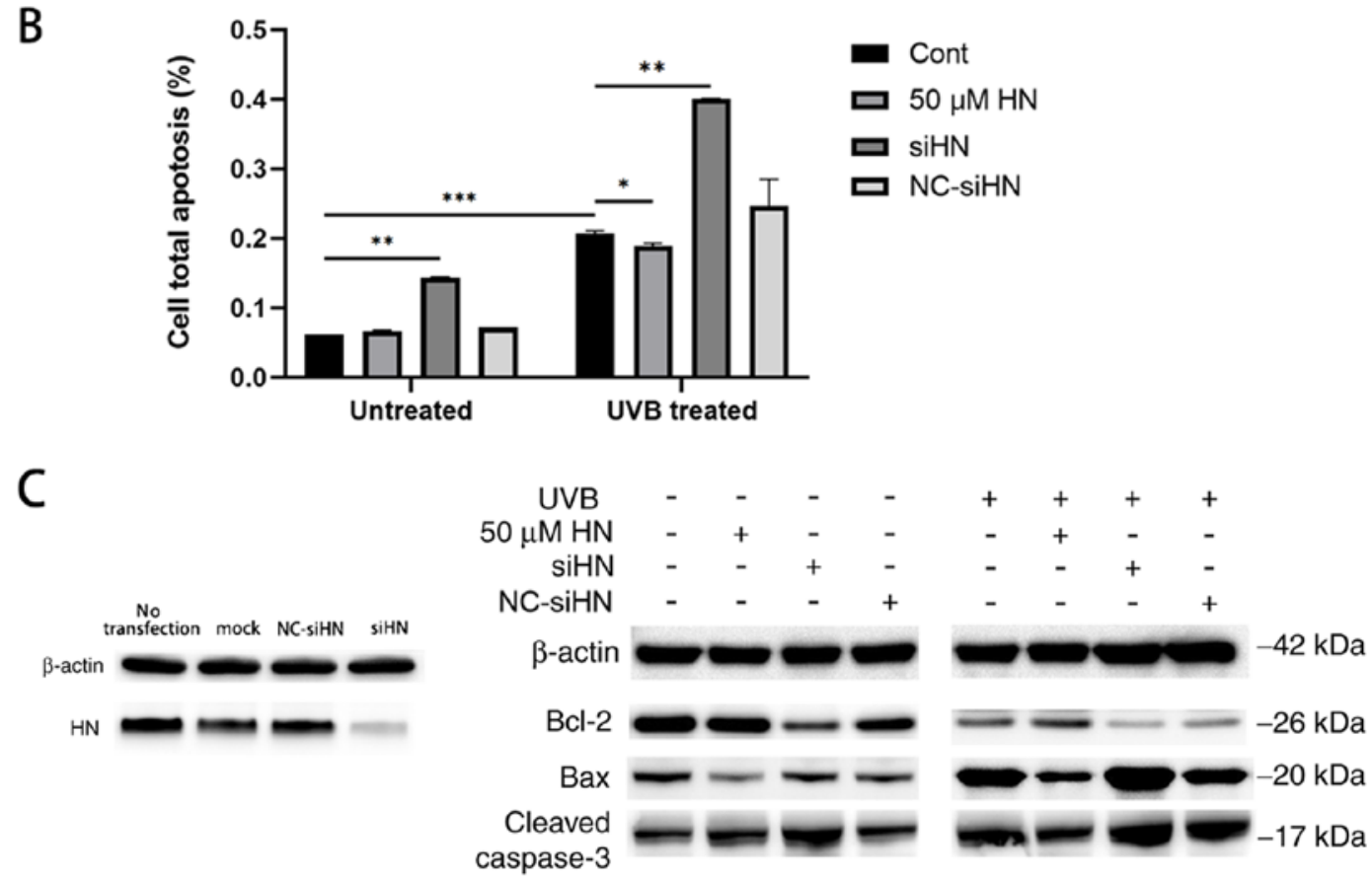

D
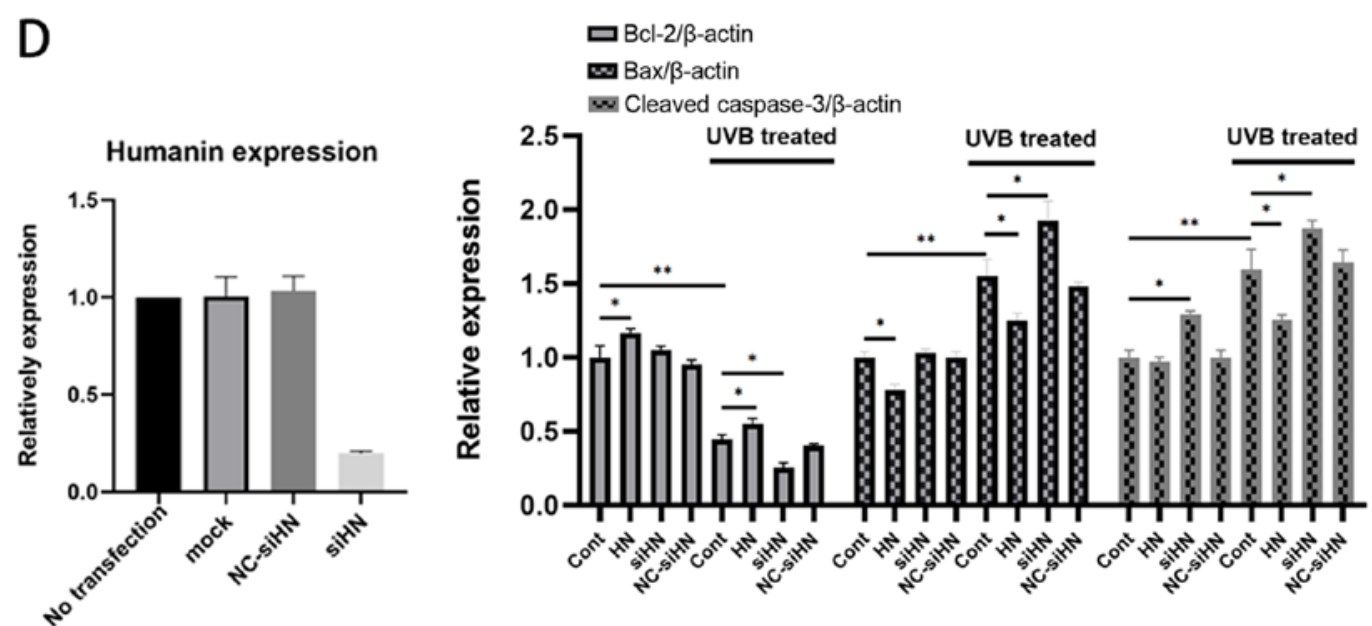

Figure 5. Apoptosis assay of HLECs under oxidative stress induced by UVB. After pretreatment with $50 \mu \mathrm{M}$ HN for $2 \mathrm{~h}$ or transfection with siRNA for $48 \mathrm{~h}$, HLECs were subjected to $30 \mathrm{~mJ} / \mathrm{cm}^{2}$ UVB radiation. (A) Annexin V/PI staining detected by flow cytometry. (B) Quantification of flow cytometry results. (C) Western blotting and (D) semi-quantification of the expression levels of the apoptosis-related proteins Bcl-2, Bax and cleaved caspase-3. Data are presented as the mean $\pm \mathrm{SD}, \mathrm{n}=3 .{ }^{*} \mathrm{P}<0.05,{ }^{* *} \mathrm{P}<0.01,{ }^{* * *} \mathrm{P}<0.001$. HN, humanin; HLECs, human lens epithelial cells; UVB, type B UV; siHN, HN siRNA; siRNA, small interfering RNA; NC, negative control; Cont, control. 
oxidative stress. Therefore, HN may maintain mitochondrial germination and normal function by promoting the initiation of mtDNA transcription, thereby increasing the resistance of HLECs to oxidative stress and preventing oxidation of lipids and proteins, which is important for maintaining the transparency of the lens (39).

HN may promote the removal of damaged depolarized mitochondria from cells (15). Mitochondrial damage caused by oxidative stress induces mitophagy to restore and maintain cellular energy metabolism, reduces mitochondria-mediated cell and tissue damage, and induces apoptosis (40). The present TEM results identified that exogenous HN pretreatment significantly enhanced mitophagy in HLECs under oxidative stress. However, as shown by results from previous studies, the relationship between $\mathrm{HN}$ and autophagy is controversial. Gong et al (41) reported that HN induced chaperone-mediated autophagy as opposed to macroautophagy. However, Han et al (42) found that $\mathrm{HN}$ induced macroautophagy in the nervous system. Cataracts are associated with lens epithelial cells and lens fiber cells. Moreover, lens fibroblasts are differentiated from lens epithelial cells. The programmed removal of organelles from differentiating lens fiber cells contributes towards lens transparency via the formation of an organelle-free zone (OFZ). Disruptions in OFZ formation are accompanied by the persistence of organelles in lens fiber cells and can contribute towards cataracts (43). Furthermore, mitochondrial autophagy can eliminate damaged or unnecessary mitochondria in HLECs, which ensures the continuous differentiation of lens epithelial cells into lens fibroblasts, and plays an important role in lens development and the maintenance of lens transparency (44). Costello et al (45) reported that the loss of mitophagy may result in retention of mitochondria in the OFZ, leading to light scattering and cataract formation. Mutations in the autophagy gene FYVE and coiled coil domain containing 1 have been confirmed to cause congenital cataracts (46). In addition, in lens fiber cells, crystallin is denatured, modified and aggregated, which can eventually lead to cataracts (10). Therefore, further research on lens fiber cells is necessary. To the best of our knowledge, the present study is the first to use TEM to demonstrate that HN significantly promoted mitochondrial autophagy in HLECs under oxidative stress. However, further investigation is required into the relationship between $\mathrm{HN}$ and mitochondrial autophagy, and its role in cataract formation. Future studies will detect autophagy-related proteins, such as microtubule-associated protein 1A/1B-light chain 3, and study the specific molecular pathways of $\mathrm{HN}$ to promote mitochondrial autophagy via the use of various autophagy regulators. Overall, the present results identified the mechanisms of $\mathrm{HN}$ in reducing intracellular ROS and clearing damaged mitochondria, which is of great significance for understanding the repair of oxidative damage and maintaining cell homeostasis.

Apoptotic cell death of HLECs under oxidative stress may involve complex mechanisms, including the mitochondrial pathway, Bcl-2 protein family and caspase-3 activation. In damaged mitochondria, the decrease in $\Delta \psi \mathrm{m}$, massive production of ROS and the release of nucleotide-modified mitochondrial proteins from mitochondria into the cytosol or nucleus play a key role in apoptosis (47). The present study demonstrated that under oxidative stress, HN may have an important role in maintaining HLEC viability, reducing cytotoxic sensitivity and preventing apoptosis. Moreover, it was found that exogenous HN pretreatment alleviated apoptosis of HLECs induced by UVB or serum starvation, while knockdown of HN increased apoptosis in HLECs. In addition, Gross et al (48) found a common checkpoint in the mammalian cell death pathway, which is at the level of the pro-apoptotic Bax and anti-apoptotic Bcl-2. The present study found that exogenous $\mathrm{HN}$ treatment upregulated $\mathrm{Bcl}-2$ protein levels and reduced the expression of Bax in HLECs treated with UVB. Furthermore, in untreated HLECs, HN pretreatment did not further reduce the apoptotic rate, but the levels of Bcl-2 and Bax proteins were altered. Thus, it is hypothesized that exogenous HN may inhibit apoptosis at the protein level in untreated conditions, but it is difficult to further reduce apoptosis due to its low basal rate. Gottardo et al (49) revealed that in untreated GH3 cells, $\mathrm{HN}$ was able to upregulate Bcl-2 expression, reduce Bax expression and significantly increase the ratio of $\mathrm{Bcl}-2$ to $\mathrm{Bax}$, which is a good index of antiapoptotic cell behavior. Therefore, $\mathrm{HN}$ may be involved in the regulation of $\mathrm{Bcl}-2$ family proteins and have a complex relationship with apoptosis-related proteins involved in the mechanism of preventing apoptosis; the binding between HN and Bax has been previously reported (12). Furthermore, caspase-3 plays a key role in the execution of apoptosis and the apoptotic pathway in the development of cataracts (50-52), and caspase activities may be activated by the release of cytochrome $c$ from mitochondria (48). Moreover, the present results suggested that $\mathrm{HN}$ reduced the levels of cleaved caspase-3 in UVB-treated HLECs.

In conclusion, the present results indicated that HN may reduce the damage and apoptosis of HLECs under oxidative stress by reducing the production of intracellular ROS and protecting the function of mitochondria. To the best of our knowledge, the present study was the first to demonstrate that exogenous HN may enhance the occurrence of intracellular mitochondrial autophagy to remove dysfunctional mitochondria, and remove harmful byproducts and oxidants to help maintain intracellular environmental balance and cell survival. Moreover, the expression levels of $\mathrm{HN}$ have been reported to decrease with age, thus a deficiency in endogenous HN may lead to insufficient oxidative resistance and may be involved in the pathogenesis of age-related diseases (53). The present study investigated the protective effect of HN on HLECs under in vitro oxidative stress. The lack of in vivo studies or clinical data is the main limitation of the present study. To examine the role of $\mathrm{HN}$ in the process of cataracts, further in vivo study of $\mathrm{HN}$ is required. Given the multiple protective effects of $\mathrm{HN}$ in HLECs under oxidative stress, HN may be a valuable potential protective molecule in the prevention and treatment of ARCs.

\section{Acknowledgements}

The authors would like to thank the Dr Chenqi Luo of the Eye Center of the Second Affiliated Hospital for excellent technical assistance.

\section{Funding}

This work was supported by the National Natural Science Foundation of China (grant no. 81670834), the National 
Natural Science Foundation of China (grant no. 81970781), the Natural Science Foundation of Zhejiang Province (gran no. LY17H090004), the National Natural Science Foundation of China (grant no. 81800807) and the National Natural Science Foundation of China (grant no. 81800869).

\section{Availability of data and materials}

The datasets used and/or analyzed during the current study are available from the corresponding author on reasonable request.

\section{Authors' contributions}

HY wrote the manuscript. HY and YC performed the experiments. HY and QY analyzed the data. YT performed the flow cytometry analysis. JZ, XT, XY and XS designed the study and interpreted the data. XS modified the manuscript. All authors read and approved the final manuscript.

\section{Ethics approval and consent to participate}

Not applicable.

\section{Patient consent for publication}

Not applicable.

\section{Competing interests}

The authors declare that they have no competing interests.

\section{References}

1. Skinner C and Miraldi Utz V: Pharmacological approaches to restoring lens transparency: Real world applications. Ophthalmic Genet 38: 201-205, 2017.

2. Beebe DC, Holekamp NM and Shui YB: Oxidative damage and the prevention of age-related cataracts. Ophthalmic Res 44: $155-165,2010$

3. Wu D, Zhao J, Wu D and Zhang J: Ultraviolet A exposure induces reversible disruption of gap junction intercellular communication in lens epithelial cells. Int J Mol Med 28: 239-245, 2011.

4. Li WC and Spector A: Lens epithelial cell apoptosis is an early event in the development of UVB-induced cataract. Free Radic Biol Med 20: 301-311, 1996.

5. Löfgren S: Solar ultraviolet radiation cataract. Exp Eye Res 156: 112-116, 2017.

6. Wolfle U, Esser PR, Simon-Haarhaus B, Martin SF, Lademann J and Schempp CM: UVB-induced DNA damage, generation of reactive oxygen species, and inflammation are effectively attenuated by the flavonoid luteolin in vitro and in vivo. Free Radic Biol Med 50: 1081-1093, 2011.

7. Hightower KR: A review of the evidence that ultraviolet irradiation is a risk factor in cataractogenesis. Doc Ophthalmol 88: 205-220, 1994

8. Dillon J: Sunlight exposure and cataract. JAMA 28: 229, 1999.

9. Ji Y, Cai L, Zheng T, Ye H, Rong X, Rao J and Lu Y: The mechanism of UVB irradiation induced-apoptosis in cataract. Mol Cell Biochem 401: 87-95, 2015.

10. Berthoud VM and Beyer EC: Oxidative stress, lens gap junctions, and cataracts. Antioxid Redox Signal 11: 339-353, 2009.

11. Gupta SK, Trivedi D, Srivastava S, Joshi S, Halder N and Verma SD: Lycopene attenuates oxidative stress induced experimental cataract development: An in vitro and in vivo study. Nutrition 19: 794-799, 2003.

12. Guo B, Zhai D, Cabezas E, Welsh K, Nouraini S, Satterthwait AC and Reed JC: Human in peptide suppresses apoptosis by interfering with Bax activation. Nature 423: 456-461, 2003.
13. Kin T, Sugie K, Hirano M, Goto YI, Nishino I and Ueno S: Humanin expression in skeletal muscles of patients with chronic progressive external ophthalmoplegia. J Hum Genet 51: 555-558, 2006.

14. Wang D, Li H, Yuan H, Zheng M, Bai C, Chen L and Pei X: Human in delays apoptosis in K562 cells by downregulation of P38 MAP kinase. Apoptosis 10: 963-971, 2005.

15. Sreekumar PG, Ishikawa K, Spee C, Mehta HH, Wan J, Yen K, Cohen P, Kannan R and Hinton DR: The mitochondrial-derived peptide human in protects RPE cells from oxidative stress, senescence, and mitochondrial dysfunction. Invest Ophthalmol Vis Sci 57: 1238-1253, 2016.

16. Klein LE, Cui L, Gong Z, Su K and Muzumdar R: A humanin analog decreases oxidative stress and preserves mitochondrial integrity in cardiac myoblasts. Biochem Biophys Res Commun 440: 197-203, 2013.

17. Hashimoto Y, Niikura T, Tajima H, Yasukawa T, Sudo H, Ito Y, Kita Y, Kawasumi M, Kouyama K, Doyu M, et al: A rescue factor abolishing neuronal cell death by a wide spectrum of familial Alzheimer's disease genes and A beta. Proc Natl Acad Sci USA 98: 6336-6341, 2001.

18. Kariya S, Takahashi N, Ooba N, Kawahara M, Nakayama H and Ueno S: Humanin inhibits cell death of serum-deprived $\mathrm{PC} 12 \mathrm{~h}$ cells. Neuroreport 13: 903-907, 2002.

19. Bachar AR, Scheffer L, Schroeder AS, Nakamura HK, Cobb LJ, Oh YK, Lerman LO, Pagano RE, Cohen P and Lerman A: Humanin is expressed in human vascular walls and has a cytoprotective effect against oxidized LDL-induced oxidative stress. Cardiovasc Res 88: 360-366, 2010.

20. Livak KJ and Schmittgen TD: Analysis of relative gene expression data using real-time quantitative PCR and the 2(-Delta Delta C(T)) method. Methods 25: 402-408, 2001.

21. Yu Y, Jiang H, Li H, Song W and Xia X: Alpha-A-crystallin protects lens epithelial cell-derived iPSC-like cells against apoptosis induced by oxidative stress. Cell Reprogram 18: 327-332, 2016.

22. Rwei P, Alex Gong CS, Luo LJ, Lin MB, Lai JY and Liu HL: In vitro investigation of ultrasound-induced oxidative stress on human lens epithelial cells. Biochem Biophys Res Commun 482: 954-960, 2017.

23. Zorov DB, Juhaszova M and Sollott SJ: Mitochondrial reactive oxygen species (ROS) and ROS-induced ROS release. Physiol Rev 94: 909-950, 2014.

24. Yen K, Lee C, Mehta $\mathrm{H}$ and Cohen P: The emerging role of the mitochondrial-derived peptide humanin in stress resistance. J Mol Endocrinol 50: R11-R19, 2013.

25. West SK, Longstreth JD, Munoz BE, Pitcher HM and Duncan DD: Model of risk of cortical cataract in the US population with exposure to increased ultraviolet radiation due to stratospheric ozone depletion. Am J Epidemiol 162: 1080-1088, 2005.

26. Yam JC and Kwok AK: Ultraviolet light and ocular diseases. Int Ophthalmol 34: 383-400, 2014.

27. Hua H, Yang T, Huang L, Chen R, Li M, Zou Z, Wang N, Yang D and Liu Y: Protective effects of lanosterol synthase up-regulation in UV-B-induced oxidative Stress. Front Pharmacol 10: 947, 2019.

28. Bodzioch M, Lapicka-Bodzioch K, Zapala B, Kamysz W, Kiec-Wilk B and Dembinska-Kiec A: Evidence for potential functionality of Nuclearly-encoded humanin isoforms. Genomics 94: 247-256, 2009.

29. Ramanjaneya M, Bettahi I, Jerobin J, Chandra P, Abi Khalil C, Skarulis M, Atkin SL and Abou-Samra AB: Mitochondrial-derived peptides are down regulated in diabetes subjects. Front Endocrinol (Lausanne) 10: 331, 2019.

30. Liu L, Yu R, Shi Y, Dai Y, Zeng Z, Guo X, Ji Q, Wang G and Zhong J: Transduced protein transduction domain linked HSP27 protected LECs against UVB radiation-induced damage. Exp Eye Res 120: 36-42, 2014.

31. Marchetti MA, Lee W, Cowell TL, Wells TM, Weissbach H and Kantorow M: Silencing of the methionine sulfoxide reductase A gene results in loss of mitochondrial membrane potential and increased ROS production in human lens cells. Exp Eye Res 83: 1281-1286, 2006.

32. Ylä-Herttuala S: Oxidized LDL and atherogenesis. Ann N Y Acad Sci 874: 134-137, 1999.

33. Stadtman ER and Levine RL: Protein oxidation. Ann N Y Acad Sci 899: 191-208, 2000.

34. Wu H, Lin L, Giblin F, Ho YS and Lou MF: Glutaredoxin 2 knockout increases sensitivity to oxidative stress in mouse lense pithelial cells. Free Radic Biol Med 51: 2108-2117, 2011. 
35. Brooks MM, Neelam S, Fudala R, Gryczynski I and Cammarata PR: Lenticular mitoprotection. Part A: Monitoring mitochondrial depolarization with JC-1 and artifactual fluorescence by the glycogen synthase kinase-3 $\beta$ inhibitor, SB216763. Mol Vis 19: 1406-1412, 2013.

36. Ristow M, Zarse K, Oberbach A, Klöting N, Birringer M, Kiehntopf M, Stumvoll M, Kahn CR and Blüher M: Antioxidants prevent health-promoting effects of physical exercise in humans. Proc Natl Acad Sci USA 106: 8665-8660, 2009.

37. Campbell CT, Kolesar JE and Kaufman BA: Mitochondrial transcription factor A regulates mitochondrial transcriptioni nitiation, DNA packaging, and genome copy number. Biochim Biophys Acta 1819: 921-929, 2012.

38. Lee C, Wu SB, Hong CH, Liao WT, Wu CY, Chen GS, Wei YH and Yu HS: Aberrant cell proliferation by enhanced mitochondrial biogenesis via mtTFA in arsenical skin cancers. Am J Pathol 178: 2066-2076, 2011.

39. Wu Q, Guo D, Bi H, Wang D and Du Y: UVB irradiation-induced dysregulation of plasma membrane calcium ATPasel and intracellular calcium homeostasis in human lens epithelial cells. Mol Cell Biochem 382: 263-272, 2013.

40. Shefa U, Jeong NY, Song IO, Chung HJ, Kim D, Jung J and Huh Y: Mitophagy links oxidative stress conditions and neurodegenerative diseases. Neural Regen Res 14: 749-756, 2019.

41. Gong Z, Tasset I, Diaz A, Anguiano J, Tas E, Cui L, Kuliawat R, Liu H, Kühn B, Cuervo AM and Muzumdar R: Humanin is an endogenous activator of chaperone-mediated autophagy. J Cell Biol 217: 635-647, 2018

42. Han K, Jia N, Zhong Y and Shang X: S14G-humanin alleviates insulin resistance and increases autophagy in neurons of APP/PS1 transgenic mouse. J Cell Biochem 119: 3111-3117, 2018.

43. Wride MA: Lens fibre cell differentiation and organelle loss: Many paths lead to clarity. Philos Trans R Soc Lond B Biol Sci 366: 1219-1233, 2011.

44. Brennan LA, McGreal-Estrada R, Logan CM, Cvekl A, Menko AS and Kantorow M: BNIP3L/NIX is required for elimination of mitochondria, endoplasmic reticulum and Golgi apparatus during eye lens organelle-free zone formation. Exp Eye Res 74: 173-184, 2018.
45. Costello MJ, Brennan LA, Basu S, Chauss D, Mohamed A, Gilliland KO, Johnsen S, Menko S and Kantorow M: Autophagy and mitophagy participate in ocular lens organelle degradation. Exp Eye Res 116: 141-150, 2013.

46. Chen J, Ma Z, Jiao X, Fariss R, Kantorow WL, Kantorow M, Pras E, Frydman M, Pras E, Riazuddin S, et al: Mutations in FYCO1 cause autosomal-recessive congenital cataracts. Am J Hum Genet 88: 827-838, 2011.

47. Balaban RS, Nemoto S and Finkel T: Mitochondria, oxidants, and aging. Cell 120: 483-495, 2005.

48. Gross A, McDonnell JM and Korsmeyer SJ: BCL-2 family members and the mitochondria in apoptosis. Genes Dev 13 1899-1911, 1999.

49. Gottardo MF, Ayala MM, Ferraris J, Zárate S, Pisera D, Candolfi M, Jaita G and Seilicovich A: Humanin inhibits apoptosis in pituitary tumor cells through several signaling pathways including NF- $\kappa$ B activation. J Cell Commun Signal 11: 329-340, 2017.

50. Roy S: Caspases at the heart of the apoptotic cell death pathway. Chemical Res Toxicol 13: 961-962, 2000.

51. Andersson M, Honarvar A, Sjöstrand J, Peterson A and Karlsson JO: Decreased caspase-3 activity in human lens epithelium from posterior sub capsular cataracts. Exp Eye Res 76: $175-182,2003$.

52. Yao H, Tang X, Shao X, Feng L, Wu N and Yao K: Parthenolide protects human lens epithelial cells from oxidative stress-induced apoptosis via inhibition of activation of caspase-3 and caspase-9. Cell Res 17: 565-571, 2007.

53. Muzumdar RH, Huffman DM, Atzmon G, Buettner C, Cobb LJ, Fishman S, Budagov T, Cui L, Einstein FH, Poduval A, et al: Humanin: A novel central regulator of peripheral insulin action. PLoS One 4: e6334, 2009.

This work is licensed under a Creative Commons Attribution-NonCommercial-NoDerivatives 4.0 International (CC BY-NC-ND 4.0) License. 